\title{
Single-Lap Joints of Similar and Dissimilar Adherends Bonded with an Acrylic Adhesive
}

\author{
A. M. G. Pinto, A. G. Magalhães, R. D. S. G. Campilho, \\ M. F. S. F. de Moura, and A. P. M. Baptista
}

\begin{abstract}
In this study, the tensile strength of single-lap joints (SLJs) between similar and dissimilar adherends bonded with an acrylic adhesive was evaluated experimen- tally and numerically. The adherend materials included polyethylene (PE), poly- propylene $(P P)$, carbon-epoxy (CFRP), and glass-polyester (GFRP) composites. The following adherend combinations were tested: $P E=P E, P E=P P, P E=C F R P, P E=G F R P, P P=P P$, $C F R P=C F R P$, and GFRP $=G F R P$. One of the objectives of this work was to assess the influence of the adherends stiffness on the strength of the joints since it significantly affects the peel stresses magnitude in the adhesive layer. The experimental results were also used to validate a new mixed-mode cohe- sive damage model developed to simulate the adhesive layer. Thus, the experimen- tal results were compared with numerical simulations performed in $A B A Q U S^{\mathbf{1}}$, including a developed mixed-mode (IpII) cohesive damage model, based on the indirect use of fracture mechanics and implemented within interface finite elements. The cohesive laws present a trapezoidal shape with an increasing stress plateau, to reproduce the behaviourof the ductile adhesive used.Agoodagreement was found between the experimental and numerical results.
\end{abstract}

\section{Keywords}

Acrylic adhesive; Cohesive damage model; Finite Element Method; Single-lap joints 


\section{INTRODUCTION}

Polyolefins are being increasingly used in industry due to their properties and reduced cost. However, while most commercial adhesives cure on these surfaces, they cannot adhere properly. This is caused by their nonpolar, nonporous, and chemically inert surfaces. Traditionally, surface preparation and pre-treatment are necessary on the bond surfaces, which make the process slow and expensive. Chemical etching, flame treating, corona discharge, plasma etching, UV irradiation, or chemical primers are amongst the most common pre-treatments [1-5]. Recently, two-part acrylic adhesives were especially developed for low surface energy materials, including polyethylene (PE) and polypropylene (PP), used in this work. These structural adhesives bond these materials without special surface preparation, leading to important advantages in industrial applications. Room temperature curing reduces the cost and oven space, heaters, and UV lamps. Open time after mixing can vary from 2 to $15 \mathrm{~min}$ and gives assembly flexibility for alignment and repositioning. After a few minutes, it is possible to handle the bonded assemblies. These adhesives can also be robotically applied. The widespread application of adhesive bonds with these materials justifies the development of accurate tools to predict their behaviour.

Different techniques were used in the past to predict the behaviour of bonded joints, especially using analytical models or the finite element method (FEM). Zou et al. [6] performed an analytical explicit study, complemented with a numerical two-dimensional FEM analysis, on the stress distributions of adhesively-bonded joints between fibre-reinforced plastic (FRP) and metallic adherends. The analytical model was based on the classical laminate plate theory, incorporating a constitutive model applicable to balanced composite joints subjected to in and out of plane loadings. A good agreement was found between the analytical and numerical through-thickness normal and shear distributions. Bogdanovich and Kizhakkethara [7] performed a three-dimensional FEM study of a carbon-epoxy (CFRP) double-strap joint under a tensile load. A method based on the sub-modelling approach available in ABAQUS ${ }^{\mathbf{1}}$ was used to predict the stress fields at the singularity regions of the joint. The method consisted on performing an initial global analysis of the structure (using a coarse mesh), followed by detailed analyses of the higher stressed regions. Some differences between stresses obtained by the traditional three-dimensional model and the sub-modelling approach were observed. In recent years, cohesive zone models (CZM) have been extensively used to predict the strength of bonded joints. In this context, triangular shape laws are the most commonly employed [8-12]. Campilho et al. [10] addressed single and double-strap repairs on unidirectional CFRP 
laminates under a tensile load. The numerical simulations were carried out in ABAQUS ${ }^{\mathbf{1}}$ using plane-strain eight-node elements, including a CZM with triangular cohesive laws in pure Modes I and II to simulate damage initiation and growth, and predict the strength of the repair. The stress distributions in the adhesive layer were also evaluated. The overlap length and the patch thickness were the geometric parameters studied. One of the most important conclusions was related to the nonproportional strength improvement of the repairs as a function of the overlap length. In fact, above a determined overlap length, the strength improvement was minimal. When adhesives with a significant ductility are used, the triangular laws are not the most adequate to simulate their behaviour. In fact, in these laws a softening region follows the peak load, which is not representative of the behaviour of these adhesives. In these cases, trapezoidal shape laws have been used to simulate the adhesive layer behaviour [13-16]. Campilho et al. [17] evaluated the tensile behaviour of adhesively bonded single-strap repairs on CFRP laminates as a function of the overlap length and the patch thickness. A numerical FEM methodology including a CZM with a trapezoidal shape in pure Modes I and II was used to simulate the ductile adhesive layer. Validation of the proposed numerical methodology was carried out with experimental results. A good agreement was found between the experiments and the numerical simulations of the failure modes, elastic stiffness, and strength of the repairs. Thus, the authors concluded that the proposed technique was adequate to simulate the mechanical behaviour of adhesively bonded assemblies with ductile adhesives. Kafkalidis and Thouless [18] simulated numerically a single-lap joint (SLJ) using a cohesive-zone approach that included the plastic strain of the adhesive, using a trapezoidal shape. The models allowed the influence of the geometry to be considered, and included in the analysis the cohesive properties of the interface and the plastic deformation of the adherends. The interfacial cohesive properties were determined in pure Modes I and II with double cantilever beam (DCB) and end-notched flexure specimens, respectively, by an inverse data fitting methodology. Using cohesive-zone parameters determined for the particular combination of materials used, the numerical predictions showed an excellent agreement with the experimental observations. Thouless et al. [19] used a cohesive-zone approach to model the mixedmode fracture of adhesively-bonded glass-polyester (GFRP) composite SLJs. A three-parameter law was used for Mode I and a two-parameter law was used for Mode II. A three-parameter Mode I traction-separation law was considered to simulate interfacial cracking followed by fibre pullout (experimentally observed for Mode I fracture). On the other hand, preliminary Mode II tests indicated that only a few fibres were pulled out during Mode II fracture. Consequently, a simple two-parameter 
traction-separation law was chosen to simulate the behaviour of the adhesive in Mode II. The experimental and numerical results revealed an excellent agreement in terms of strength and failure mechanisms of the joints.

In this study, the tensile strength of SLJs of similar and dissimilar adherends bonded with an acrylic adhesive was evaluated. The experiments were used to validate a developed trapezoidal mixed-mode (I DI) cohesive damage model based on the indirect use of fracture mechanics and implemented within interface finite elements. The cohesive laws present an increasing stress plateau to simulate the experimentally observed behaviour of the adhesive used. The joints included combinations of the following materials: PE, PP, CFRP, and GFRP composites. The influence of the adherend's stiffness on the joint's strength was also addressed, since it significantly influences the stress distributions in the adhesive layer.

\section{COHESIVE DAMAGE MODEL}

\subsection{Model Description}

The objective of the proposed model was to define an empirical constitutive mixed-mode damage law which can reproduce the behaviour of the adhesive used in the bonded joints. The adhesive used in this work presents elasto-plastic behaviour in pure Modes I and II that can be well replicated by the trapezoidal constitutive law of Fig. 1. Considering a pure mode loading (pure Mode I or II), there is a linear relationship between tractions, $\boldsymbol{\sigma}$, and relative displacements, $\boldsymbol{\delta}_{\mathrm{r}}$, before damage starts to grow

$$
\boldsymbol{\sigma}=\mathbf{E} \boldsymbol{\delta}_{\mathbf{r}}
$$

where $\mathrm{E}$ is a diagonal matrix containing the interface stiffnesses $\left(e_{i},{ }^{1 / 4} \mathrm{I}\right.$, II). These are defined as being the ratio between the Young's (Mode I) or shear modulus (Mode II), and the adhesive thickness $\left(t_{\mathrm{A}}\right)$. In the puremode damage model, the nonlinear hehaviour initiates when the stress reaches the softening strength $\left(\sigma_{\mathrm{s}, i}\right)$. The constitutive law is

$$
\boldsymbol{\sigma}=(\mathbf{I}-\mathbf{D}) \mathbf{E} \boldsymbol{\delta}_{\mathbf{r}},
$$

where $\mathrm{I}$ is the identity matrix and $\mathrm{D}$ is a diagonal matrix containing, in the position corresponding to mode $i\left(i \frac{1}{4} \mathrm{I} \mathrm{I}, \mathrm{II}\right)$, the damage parameter, $d$. In the first span $\left(\bar{\delta}_{1, i} \leq \delta_{i} \leq \delta_{2, i}\right)$, the damage parameter is given by

$$
d=\frac{\left(\delta_{i}-\delta_{1, i}\right)\left(\delta_{2, i}-\alpha_{i} \delta_{1, i}\right)}{\delta_{i}\left(\delta_{2, i}-\delta_{1, i}\right)},
$$




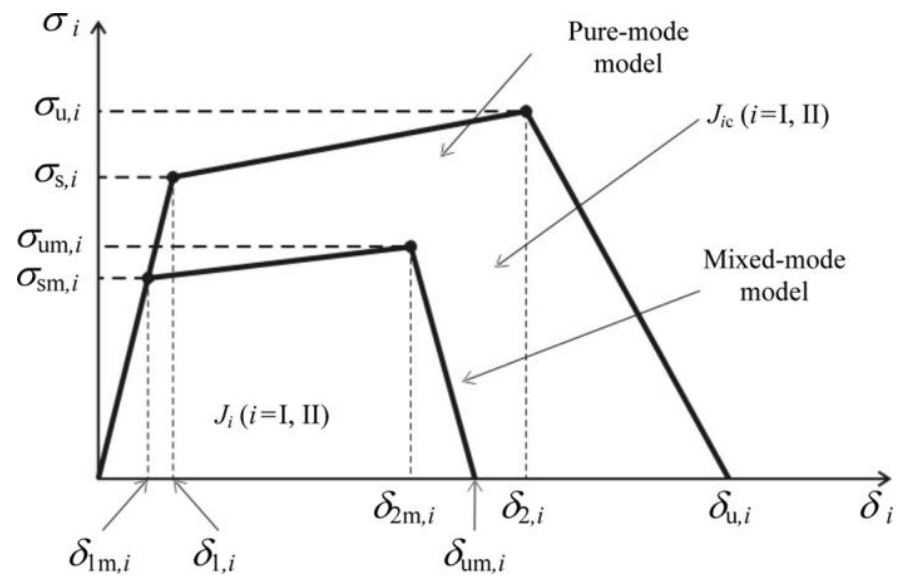

FIGURE 1 The trapezoidal softening law for pure-mode and mixed-mode.

where $a_{i}$ stands for the strength ratio

$$
\alpha_{i}=\frac{\sigma_{\mathrm{u}, i}}{\sigma_{\mathrm{s}, i}}
$$

and $\sigma_{\mathrm{u}, i}$ the ultimate local strength in each pure mode. In the second branch of the softening process $\left(\delta_{2, i} \leq \delta_{i} \leq \delta_{\mathrm{u}, i}\right)$, corresponding to the reduction of stresses from $\sigma_{\mathbf{u}, i}$ to zero, the damage parameter is

$$
d=1+\frac{\alpha_{i} \delta_{1, i}\left(\delta_{i}-\delta_{\mathrm{u}, i}\right)}{\delta_{i}\left(\delta_{\mathrm{u}, i}-\delta_{2, i}\right)}
$$

The maximum relative displacement, $d_{\mathrm{u}, i}$, at which complete failure occurs, is obtained by equating the area under the softening curve to the respective critical fracture energy $\left(J_{i c}\right)$,

$$
J_{i c}=\frac{\sigma_{\mathrm{s}, i}}{2}\left(\delta_{2, i}+\alpha_{i}\left(\delta_{\mathrm{u}, i}-\delta_{1, i}\right)\right) .
$$

Usually, bonded joints are under mixed-mode loading. Consequently, a mixed-mode damage model, which consists on an extension of the pure mode one, was also developed. The nonlinear behaviour takes place when the quadratic stress criterion

$$
\left(\frac{\sigma_{\mathrm{I}}}{\sigma_{\mathrm{s}, \mathrm{I}}}\right)^{2}+\left(\frac{\sigma_{\mathrm{II}}}{\sigma_{\mathrm{s}, \mathrm{II}}}\right)^{2}=1
$$


is satisfied. Considering Eq. (1), Eq. (7) can be rewritten as a function of the relative displacements

$$
\left(\frac{\delta_{1 \mathrm{~m}, \mathrm{I}}}{\delta_{1, \mathrm{I}}}\right)^{2}+\left(\frac{\delta_{1 \mathrm{~m}, \mathrm{II}}}{\delta_{1, \mathrm{II}}}\right)^{2}=1,
$$

where $d_{1 \mathrm{~m}, i}\left(i \mathbb{T}_{4}\right.$ II $)$ are the relative displacements in each mode corresponding to the nonlinear behaviour onset. Defining an equivalent mixed-mode displacement,

$$
\delta_{\mathrm{m}}=\sqrt{\delta_{\mathrm{I}}^{2}+\delta_{\mathrm{II}}^{2}},
$$

ðр

and a mixed-mode ratio,

$$
\beta=\frac{\delta_{\mathrm{II}}}{\delta_{\mathrm{I}}},
$$

it is possible to establish $d_{1 \mathrm{~m}, i}(i \quad 1 / 4 \mathrm{I}$, II $)$ as a function of the corresponding equivalent mixed-mode displacement and $b$

$$
\delta_{1 \mathrm{~m}, \mathrm{I}}=\frac{\delta_{1 \mathrm{~m}}}{\sqrt{1+\beta^{2}}} ; \quad \delta_{1 \mathrm{~m}, \mathrm{II}}=\frac{\delta_{1 \mathrm{~m} \beta}}{\sqrt{1+\beta^{2}}} .
$$

Substituting these quantities in Eq. (8) allows defining the mixedmode relative displacement at the onset of the softening process $\left(d_{1 \mathrm{~m}}\right)$,

$$
\delta_{1 \mathrm{~m}}=\delta_{1, \mathrm{I}} \delta_{1, \mathrm{II}} \sqrt{\frac{1+\beta^{2}}{\delta_{1, \mathrm{II}}^{2}+\beta^{2} \delta_{1, \mathrm{I}}{ }^{2}}} .
$$

The second inflexion point $\left(d_{2 \mathrm{~m}}\right)$ is predicted using also a quadratic stress criterion

$$
\left(\frac{\sigma_{\mathrm{I}}}{\sigma_{\mathrm{u}, \mathrm{I}}}\right)^{2}+\left(\frac{\sigma_{\mathrm{II}}}{\sigma_{\mathrm{u}, \mathrm{II}}}\right)^{2}=1,
$$

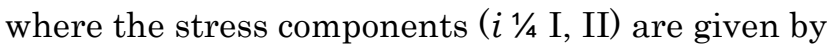

$$
\sigma_{i}=\sigma_{\mathrm{sm}, i}+\frac{\sigma_{\mathrm{u}, i}-\sigma_{\mathrm{s}, i}}{\delta_{2, i}-\delta_{1, i}}\left(\delta_{i}-\delta_{1 \mathrm{~m}, i}\right) .
$$

Combining Eqs. (9), (10), (13), and (14), the equivalent mixed-mode relative displacement at the second inflexion point $\left(d_{2 \mathrm{~m}}\right)$ is determined. The equivalent ultimate relative displacement $\left(d_{\mathrm{um}}\right)$ corresponding to crack growth is obtained using the linear energetic criterion

$$
\frac{J_{\mathrm{I}}}{J_{\mathrm{Ic}}}+\frac{J_{\mathrm{II}}}{J_{\mathrm{IIc}}}=1,
$$


where $J_{i}\left(i \mathbb{T}_{4} \mathrm{II}\right)$, representing the energy dissipated in each mode at complete failure, can be given by the area of the smaller trapezoid of Fig. 1,

$$
J_{i}=\frac{\sigma_{\mathrm{sm}, i} \delta_{2 \mathrm{~m}, i}+\sigma_{\mathrm{um}, i}\left(\delta_{\mathrm{um}, i}-\delta_{1 \mathrm{~m}, i}\right)}{2} .
$$

$r_{\mathrm{sm}, i}$ and $r_{\mathrm{um}, i}$ are obtained from the respective relative displacements and using Eqs. (1) and (14), respectively. Combining Eqs. (9), (10), (15), and (16), the equivalent mixed-mode ultimate relative displacement $\left(d_{\mathrm{um}}\right)$ is determined. The damage parameter under mixed-mode loading is then calculated using the equivalent mixed-mode quantities, i.e., $d_{\mathrm{m}}$, $d_{1 \mathrm{~m}}, d_{2 \mathrm{~m}}$, and $d_{\mathrm{um}}$ in Eqs. (3) or (5). The strengths ratio $a_{\mathrm{m}}$ is given by Eq. (4) using the equivalent stresses $r_{\mathrm{sm}}$ and $r_{\mathrm{um}}$.

\subsection{Cohesive Parameters}

The developed cohesive damage model was implemented within interface finite elements and introduced in the numerical models to simulate a $t_{\mathrm{A}} 1 / 40.2 \mathrm{~mm}$ ductile adhesive layer of $3 \mathrm{M} \mathrm{DP}-8005^{\mathbf{1}}$ (3M, St. Paul, MN, USA) in pure Modes I and II. Thus, the developed methodology incorporates $t_{\mathrm{A}}$ in its formulation. The cohesive parameters in pure Modes I and II to be defined are the softening strengths $\left(r_{\mathrm{s},}\right)$, the maximum strengths $\left(r_{\mathrm{u}, i}\right)$, the second inflexion points $\left(d_{2, i}\right)$, and the critical fracture energies $\left(J_{i c}\right)$. It is known that adhesives behave differently as a thin layer or as a bulk [20-22]. The deformationconstraining effects caused by the adherends and the respective mixed-mode crack propagation for the adhesive as a thin layer justify this difference. In this work, the cohesive parameters in pure Mode II were obtained with an inverse method, which consisted on a fitting procedure between the block-shear test method [23] experimental load-displacement $(P-d)$ curves and the numerical simulations. This procedure was adopted since the adhesive layer is mainly loaded in shear, while normal stresses are minimized. On the other hand, for the pure Mode I cohesive law, some of the parameters $\left(r_{\mathrm{s}, \mathrm{I}}, r_{\mathrm{u}, \mathrm{I}}\right.$, and, $d_{2, \mathrm{I}}$ ) were assumed to be equal to the corresponding bulk quantities, while $J_{\text {Ic }}$ was determined from DCB tests. The authors emphasize that, ideally, a similar procedure to the pure Mode II law should have been used. Moreover, Andersson and Stigh [20] concluded that in pure Mode I, using the DCB test, the local strengths $\left(r_{\mathrm{s}, \mathrm{I}}\right.$ and $\left.r_{\mathrm{u}, \mathrm{I}}\right)$ of a thin ductile adhesive layer are of the same order of magnitude as the tensile strength measured in bulk tests. However, they also concluded that this is not valid concerning the fracture strain of the adhesive. Since Yang et al. [24] demonstrated that the parameters $d_{2, i}$ 
do not significantly influence the numerical results, $d_{2, \text { I }}$ was calculated by the product of the average failure strain obtained in the adhesive bulk tests with $t_{\mathrm{A}}$. The first inflexion points $\left(d_{1, i}\right)$ were calculated from the initial stiffness of the adhesive in tension or shear and the respective value of $r_{\mathrm{s}, i .}$. A similar procedure was successfully applied by Campilho et al. [17] on CFRP single-strap repairs under a tensile load.

\section{EXPERIMENTAL WORK}

The geometry and dimensions of the adhesive bulk specimen used to obtain the cohesive law in pure Mode I, and the respective setup in the testing machine, are presented in Figs. 2a and b, respectively. Figure 3 presents the (a) block-shear joints and (b) SLJs (geometry, boundary conditions, and dimensions in $\mathrm{mm}$ ). PE adherends were used in the block-shear tests, whose stress-strain ( $r-e)$ law was obtained experimentally with bulk tests and introduced in the numerical simulations to simulate their behaviour. For the SLJs, several combinations of materials for the adherends were considered: $\mathrm{PE}$, PP, CFRP, and GFRP composites, this last with random fibre orientation. Two different configurations were considered for the CFRP adherends: $1.2 \mathrm{~mm}$ thickness unidirectional pultruded composite (CFRP1) and $2.4 \mathrm{~mm}$ thickness $\left[0_{2}, 90_{2}, 0_{2}, 90_{2}\right]_{\text {s lay-up composite }}$ (CFRP2). Table 1 presents the adherend combinations tested and the respective thickness $\left(t_{\mathrm{S}}\right)$ and width $(B)$. The remaining dimensions were kept constant (Fig. 3b). Joints were considered between similar adherends of all the stated materials, and between PE and the remaining materials. The two-component structural acrylic adhesive DP$8005^{1}$ from $3 \mathrm{M}$ was used (Young's modulus, E1/4590 MPa and Poisson's

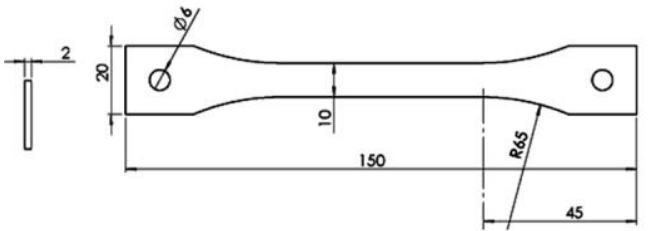

(a)

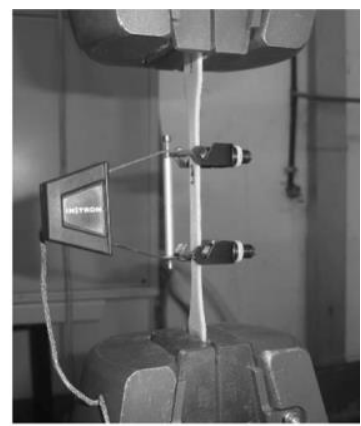

(b)

FIGURE 2 Geometry and dimensions (in $\mathrm{mm}$ ) of the (a) adhesive bulk specimen and (b) respective setup in the testing machine. 


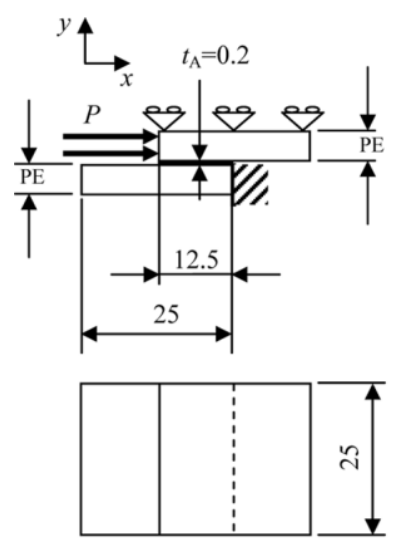

(a)

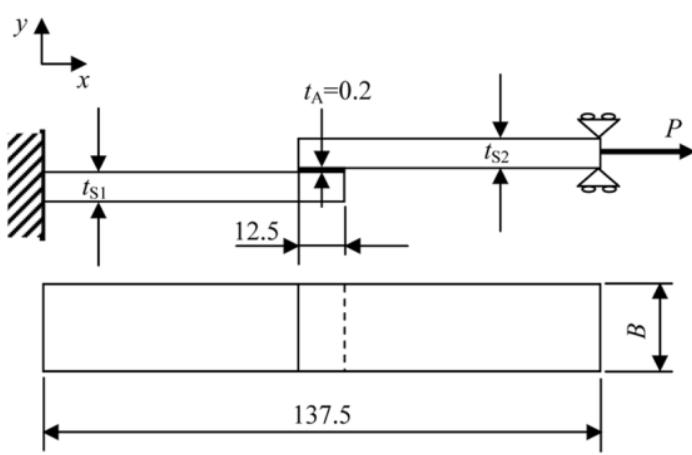

(b)

FIGURE 3 Geometry, boundary conditions, and dimensions (in $\mathrm{mm}$ ) of the (a) block-shear joints and (b) SLJs.

ratio, $\mathbf{n}$ 19.35). The $r$-e laws up to failure of the PE and PP adherends were obtained experimentally with bulk tests and introduced in the numerical models to simulate their behaviour. Values of $E_{4} / 930 \mathrm{MPa}$ $\mathrm{MPa}$ and $\mathbf{n} 10.3$ were used to simulate the elastic behaviour of the PE adherends, while for the $\mathrm{PP}$ adherends $\mathbb{Z}_{4} 1400 \mathrm{MPa}$ and $\mathbf{W}_{4} 0.3$ were considered. For the CFRP and GFRP adherends, only the orthotropic elastic behaviour was considered, since no plastic deformation of these materials was observed. The elastic properties of CFRP and GFRP adherends are presented in Table 2 [10].

Different surface preparation techniques were used for each adherend material. The PE and PP adherends were only cleaned with

TABLE 1 Dimensions (in $\mathrm{mm}$ ) of the Adherends' Combinations Evaluated

\begin{tabular}{lccccc}
\hline & \multicolumn{2}{c}{ Adherend 1} & & \multicolumn{2}{c}{ Adherend 2} \\
\cline { 2 - 3 } \cline { 5 - 6 } Adherend 1=Adherend 2 & Thickness $\left(t_{\mathrm{S} 1}\right)$ & Width $(B)$ & & Thickness $\left(t_{\mathrm{S} 2}\right)$ & Width $(B)$ \\
\hline PE=PE & 6 & 25 & & 6 & 25 \\
PP=PP & 6 & 25 & & 6 & 25 \\
CFRP1=CFRP1 & 1.2 & 15 & & 1.2 & 15 \\
CFRP2=CFRP2 & 2.4 & 15 & & 2.4 & 15 \\
GFRP=GFRP & 5 & 15 & & 5 & 15 \\
PE=PP & 6 & 25 & & 6 & 25 \\
PE=CFRP1 & 6 & 15 & & 1.2 & 15 \\
PE=CFRP2 & 6 & 15 & & 2.4 & 15 \\
PE=GFRP & 6 & 15 & & 5 & 15 \\
\hline
\end{tabular}




\begin{tabular}{|c|c|c|}
\hline \multicolumn{3}{|c|}{ CFRP unidirectional lamina or pultru } \\
\hline$E_{1} 1 / 41.09 \mathrm{E}$ p $05 \mathrm{MPa}$ & $\mathbf{n}_{12} 1 / 4.342$ & $G_{12} 1 / 4315 \mathrm{MPa}$ \\
\hline$E_{2} 1 / 8819 \mathrm{MPa}$ & $\mathbf{n}_{13} 1 / 40.342$ & $G_{13} 1 / 4315 \mathrm{MPa}$ \\
\hline$E_{3} 1 / 8819 \mathrm{MPa}$ & $\mathbf{n}_{23} 1 / 4.380$ & $G_{23}{ }^{1 / 43200 \mathrm{MPa}}$ \\
\hline \multicolumn{3}{|l|}{ GFRP lamina } \\
\hline$E_{1} 1 / 432360 \mathrm{MPa}$ & $\mathbf{n}_{12} \frac{1 / 4}{0.280}$ & $G_{12} \frac{1 / 4}{12800 \mathrm{MPa}}$ \\
\hline$E_{2} 1 / 432360 \mathrm{MPa}$ & $\mathbf{n}_{13} 1 / 40.240$ & $G_{13} \frac{1 / 4}{1300 \mathrm{MPa}}$ \\
\hline$E_{3} 1 / 46600 \mathrm{MPa}$ & $\mathbf{n}_{23}{ }^{1 / 4} 0.240$ & $G_{23} \frac{1 / 4}{1300 \mathrm{MPa}}$ \\
\hline
\end{tabular}

(1-fibres direction, 2-transverse direction, 3-thickness direction).

isopropanol. With this method, cohesive failures were guaranteed to occur [25]. The CFRP and GFRP adherends were abraded with 100 grit sand paper in the bonded regions and cleaned with acetone. The shear strength of the joints was determined by the lap shear test method [26,27]. The value of $t_{\mathrm{A}}$ was fixed at $0.2 \mathrm{~mm}$ with calibrated glass microspheres mixed with the adhesive. The adhesive excess at the overlap edges was removed in all joints. Pressure was applied to the lap joint during the curing cycle by one spring clamp. The joints' bonding and assembly was accomplished with a specially manufactured tool, allowing the standardised joint preparation technique to be used repeatedly. Tabs at the ends of the SLJs were bonded to assure a correct alignment. The specimens were cured at room temperature for one week prior to testing. The adhesive bulk, block-shear, and single-lap specimens were tested using an Instron ${ }^{1} 4208$ (Norwood, MA, USA) testing machine at room temperature under displacement control $(1.3 \mathrm{~mm}=\mathrm{min})$. Throughout this work, the average shear strength $\left(s_{\mathrm{m}}\right)$ was used to measure the joints' strength, and was calculated as the peak load of each test divided by the measured bond area. The reported test values in this work are an average of at least five measurements. The failure modes were determined by visual inspection.

\section{NUMERICAL ANALYSIS}

The numerical analyses including the cohesive damage model presented in Section 2.1 were carried out in ABAQUS $^{\mathbf{1}}$ (Dassault Systèmes, Suresnes, France). A nonlinear material and geometrical analysis was performed. Plane stress 8-node rectangular solid finite elements available in ABAQUS ${ }^{1}$ were used. Figure 4 shows a detail of the mesh used for the $\mathrm{PE}=\mathrm{PE}$ joint at the overlap region. The interface elements, including the developed cohesive damage model, employed to simulate the adhesive layer behaviour, are shown in Fig. 4 by the small crosses. Sixteen elements were used for the 


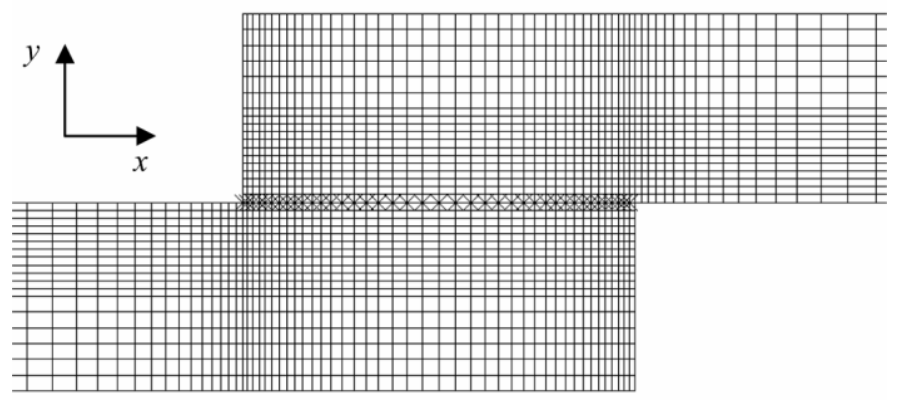

FIGURE 4 Detail of the mesh used for the PE=PE joint at the overlap region.

adherends in the thickness direction, and 40 elements were employed along the overlap. Furthermore, biasing effects were used, allowing for a more refined mesh where stress gradients are known to be greater, i.e., the overlap edges [10,28-31]. The boundary conditions imposed in the numerical models (Figs. 3a and b) aimed to reproduce the experimental testing conditions. As mentioned earlier, the complete $r-e$ curves of the PE and PP adherends were introduced in the numerical models to simulate numerically their plastic behaviour.

\section{RESULTS}

\subsection{Determination of the Cohesive Laws}

Figure 5 shows the adhesive bulk $r$-e curves and the pure Mode I cohesive law approximation. $r_{\mathrm{s}, \mathrm{I}}$ was equalled to $r_{\mathrm{u}, \mathrm{I}}$, to replicate the experimental behaviour of the adhesive in pure Mode I. The second inflexion point $\left(d_{2, \mathrm{I}}\right)$ was obtained from the product of the average experimental failure strain and $t_{\mathrm{A}}$. $J_{\text {Ic }}$ was determined from DCB tests with mild steel adherends, and an average value of $J_{\text {Ic }} 1 / 41.1 \mathrm{~N}=\mathrm{mm}$ was obtained. Figure 6 compares the block-shear test experimental $P$ $d$ curves with the numerical approximation after the fitting procedure, which allowed defining the cohesive law in pure mode II. The cohesive parameters of the pure Mode I and II laws are presented in Table 3 .

\subsection{Stress Analysis}

An elastic stress analysis in the adhesive layer was performed to assess the influence of the stiffness of the adherends on the throughthickness normal $\left(r_{\mathrm{y}}\right)$ and shear $\left(s_{\mathrm{xy}}\right)$ stresses in the adhesive layer 


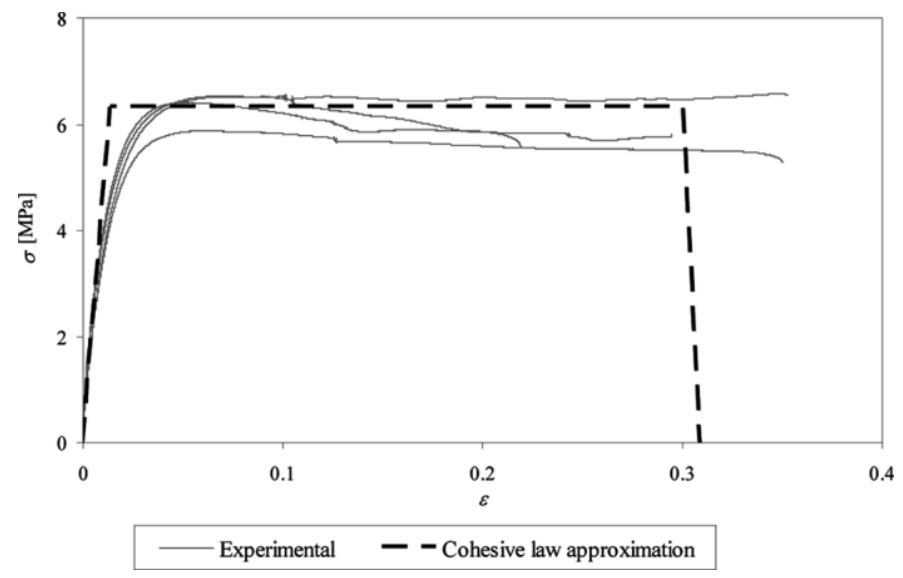

FIGURE 5 Adhesive bulk $r$-e curves and pure Mode I cohesive law approximation.

and on the strength of the joints. In this work, $r_{\mathrm{y}}$ and $s_{\mathrm{xy}}$ stresses are normalized by $s_{\text {avg }}$, the average shear stress in the adhesive layer along the bond length for the respective joint. $x=L$ represents the overlap normalized distance from the joints edge. Figures 7 and 8 present $r_{\mathrm{y}}$ and $s_{\mathrm{xy}}$ stresses, respectively, for the joints with similar adherends. Regardless of the adherend material, the typical profiles for these joints were obtained [10,32-34], with $r_{\mathrm{y}}$ stresses approximately nil

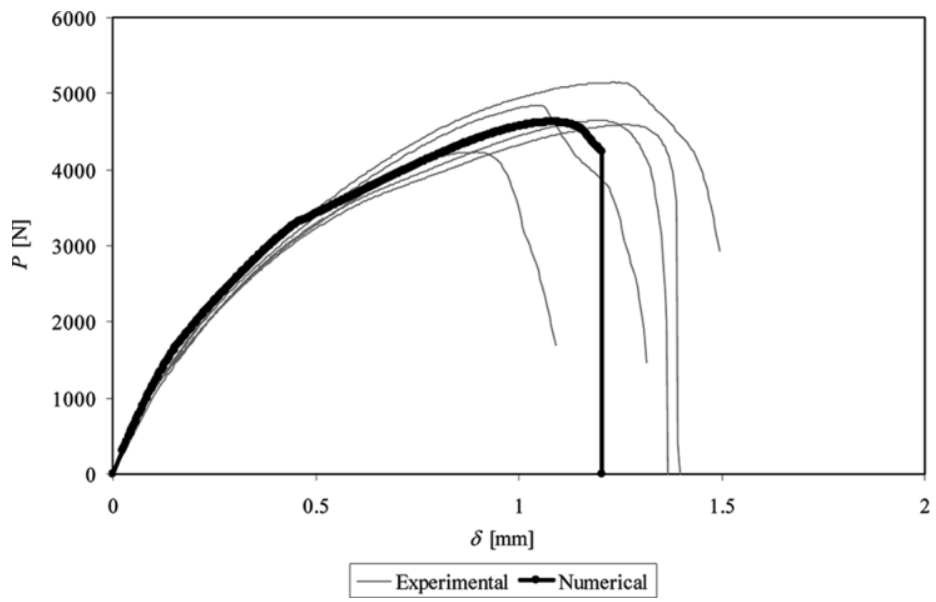

FIGURE 6 Block-shear test experimental $P$ - $d$ curves with the numerical approximation after the fitting procedure. 
TABLE 3 Cohesive Parameters of the Adhesive Layer in Pure Modes I and II

\begin{tabular}{lcccc}
\hline$i$ & $J_{i c}[\mathrm{~N}=\mathrm{mm}]$ & $\mathrm{r}_{\mathrm{s}, i}[\mathrm{MPa}]$ & $\mathrm{r}_{\mathrm{u}, i}[\mathrm{MPa}]$ & $\mathrm{d}_{2, i}[\mathrm{~mm}]$ \\
\hline $\mathrm{I}$ & 1.1 & 6.3 & 6.3 & 0.058 \\
$\mathrm{II}$ & 6.0 & 8.9 & 14.5 & 0.35 \\
\hline
\end{tabular}

at the inner overlap region, peaking at the overlap edges. $\mathrm{s}_{\mathrm{xy}}$ peak stresses were also observed at the overlap edges. Both stresses presented a similar tendency, i.e., the highest gradients were observed for the PE and PP joints, due to their higher flexibility and consequent bending at the overlap region. Slightly smaller peak stresses were observed for the CFRP1 joints, while the flattest stress distributions, especially concerning shear stresses, were obtained for the GFRP and CFRP2 joints (corresponding to the highest joint stiffness). These results point towards a trend of increasing strength of the joints in the order mentioned above, due to the gradual reduction of stresses at the overlap edges, known to be the damage initiation regions in these joints [35,36]. Figures 9 and 10 show $\mathrm{r}_{\mathrm{y}}$ and $\mathrm{s}_{\mathrm{xy}}$ stresses, respectively, for the joints combining PE with other materials. In all cases, PE is the upper adherend (Figs. 11 and 12). Under these conditions, where the $\mathrm{PE}$ adherend always presents a smaller stiffness than the other
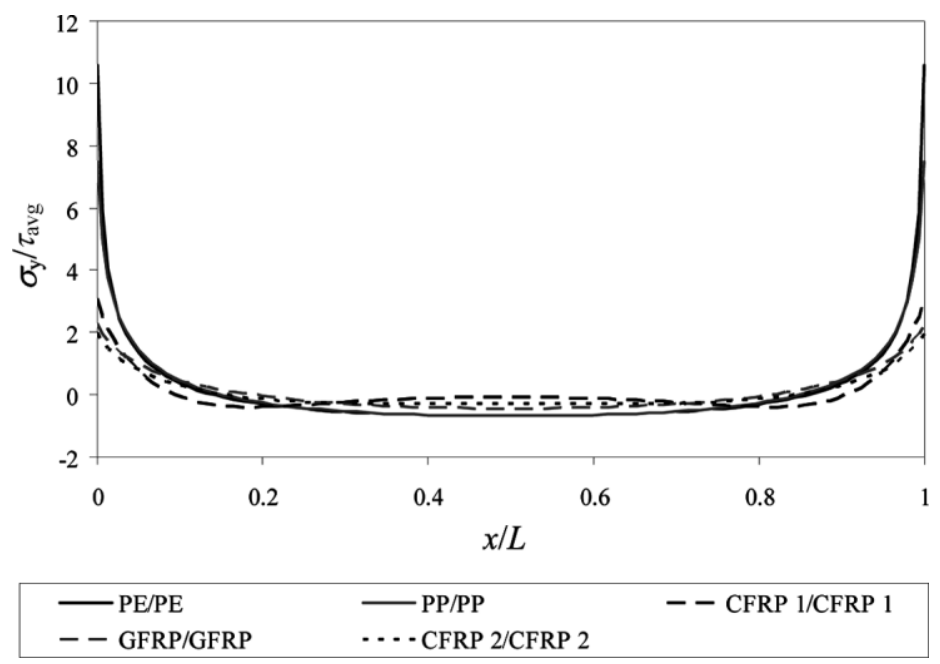

FIGURE $7 \mathrm{r}_{\mathrm{y}}$ stress distributions in the adhesive layer for the SLJs with similar adherends. 


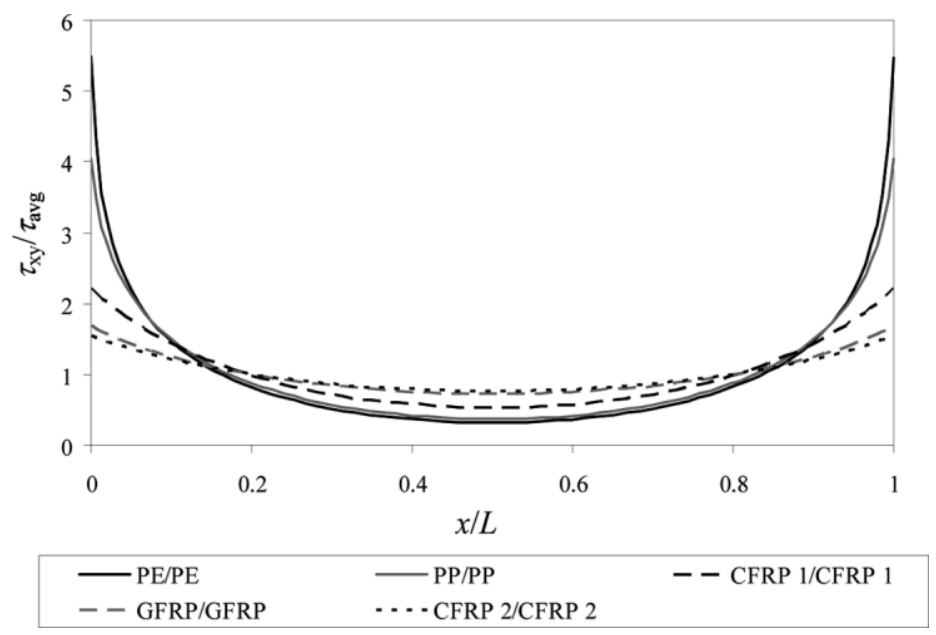

FIGURE $8 s_{\mathrm{xy}}$ stress distributions in the adhesive layer for the SLJs with similar adherends.

material adherend, $r_{\mathrm{y}}$ and $s_{\mathrm{xy}}$ stresses exhibit smaller magnitude peaks at one of the overlap edges. In fact, $r_{\mathrm{y}}$ stresses present a smaller peak at the overlap edge at $x=L 1 / 41$, since this region corresponds to the edge of the stiffer adherend, where transverse deformations are smaller (Fig. 11). Consequently, $r_{\mathrm{y}}$ peel peak stresses are smaller in

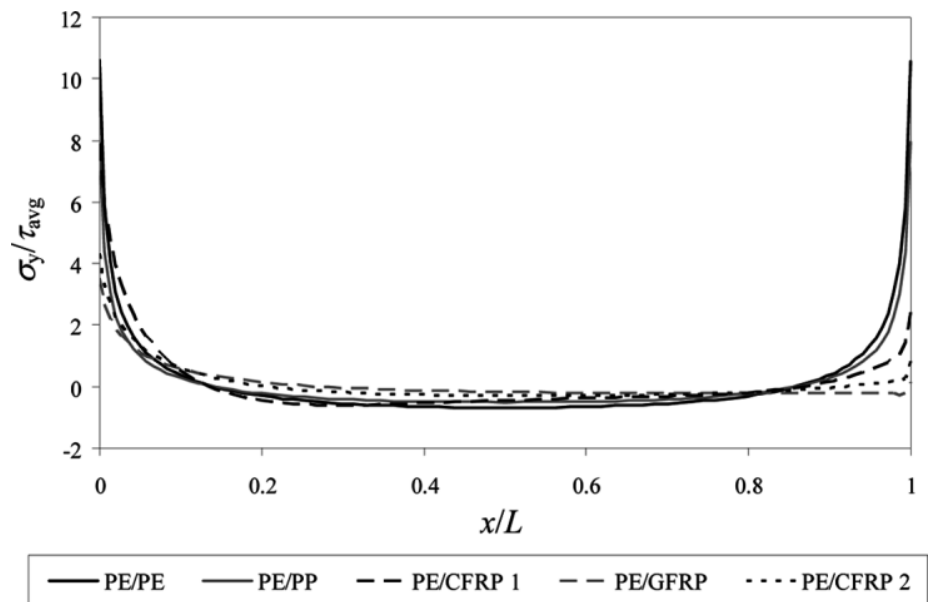

FIGURE $9 r_{\mathrm{y}}$ stress distributions in the adhesive layer for the SLJs combining PE with other materials. 


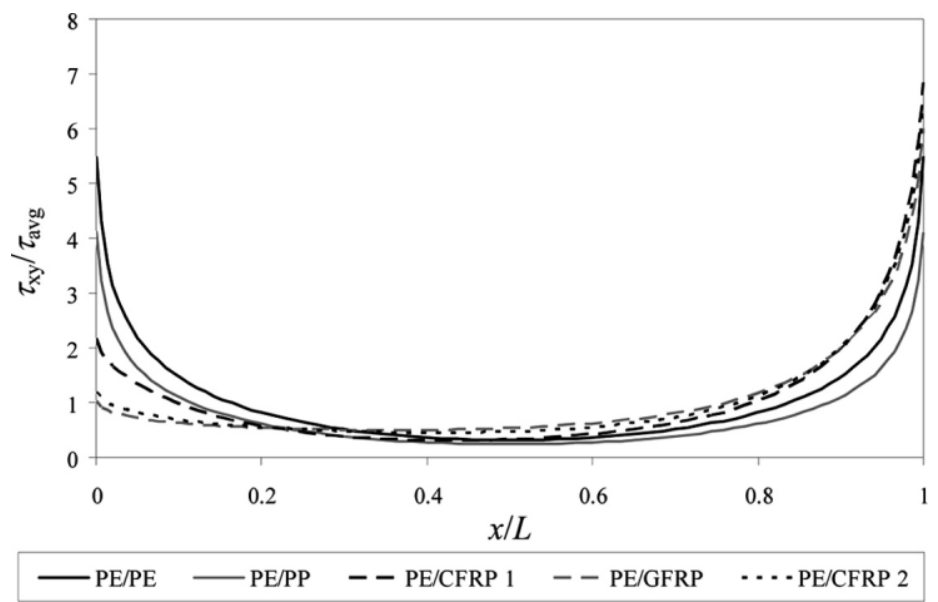

FIGURE $10 s_{\mathrm{xy}}$ stress distributions in the adhesive layer for the SLJs combining PE with other materials.

magnitude than at $x=L^{1 / 40}$, where the bigger flexure of the $\mathrm{PE}$ adherend edge induces higher magnitude $r_{\mathrm{y}}$ stresses. On the other hand, $s_{\mathrm{xy}}$ stresses show a smaller magnitude peak at $x=L 1 / 40$, because of the increasing longitudinal deformation of the PE adherend from $x=L^{1} / \theta$ up to $x=L^{1 / 4}$ (Fig. 12). Since the other material adherend undergoes a smaller longitudinal deformation at the overlap region, higher magnitude $s_{\mathrm{xy}}$ stresses develop towards $x=L / 41$. On both stress distributions, the gradual stiffness increase of the lower and stiffer adherend progressively decreases peak stresses at the mentioned regions.

\subsection{Mechanical Behaviour}

The deformed configuration immediately before failure is presented in Fig. 13 for the joints combining PE with other materials, in the

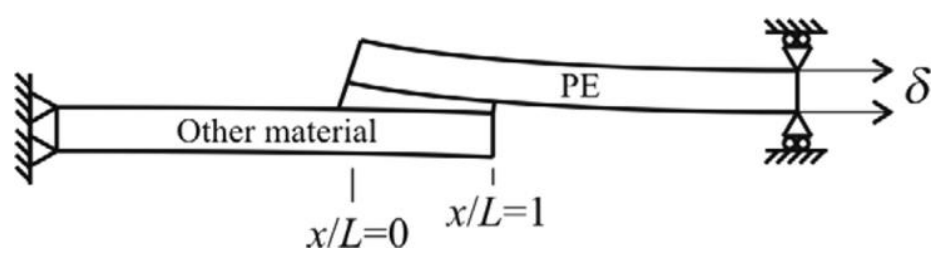

FIGURE 11 Schematic representation of the transverse deformation for the SLJs combining PE with other materials. 


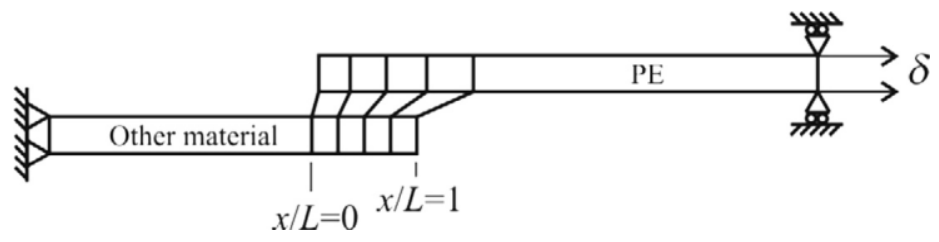

FIGURE 12 Schematic representation of the longitudinal deformation for the SLJs combining PE with other materials.

following order: $\mathrm{PE}=\mathrm{PE}, \quad \mathrm{PE}=\mathrm{PP}, \quad \mathrm{PE}=\mathrm{CFRP} 1, \quad \mathrm{PE}=\mathrm{GFRP}$, and $\mathrm{PE}=\mathrm{CFRP2}$. The gradual increase on the stiffness of the non-PE adherends in the order presented leads to the reduction of the joints bending and corresponding decrease in $r_{\mathrm{y}}$ peel and $s_{\mathrm{xy}}$ stresses, mentioned in the previous section. The failures were essentially cohesive in the adhesive layer [(Fig. 14a and b) show cohesive failures in a $\mathrm{PE}=\mathrm{PE}$ and a CFRP2=CFRP2 joint, respectively], with the exception of the joints with GFRP adherends. In fact, in these joints failures occurred within the GFRP with fibre pull-out (Fig. 14c). It should be emphasized that, with a simple surface preparation technique, adhesive failures were prevented in the $\mathrm{PE}$ and $\mathrm{PP}$ adherends, which are extremely difficult to bond, as mentioned earlier [25]. Figures 15-20 present some examples of the experimental and numerical $P d$ curves for six adherend combinations. Figures $15-17$ pertain to joints with similar adherends, while Figs. 18-20 correspond to joints combining PE with other materials. An overall good agreement between the experiments and the numerical simulations is observed in all cases. These results also show that using more flexible adherends leads to a smooth

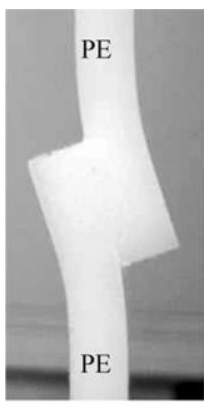

(a)

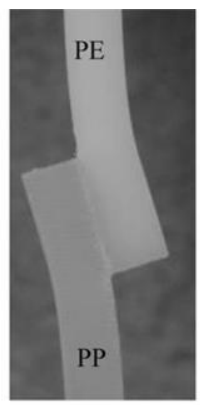

(b)

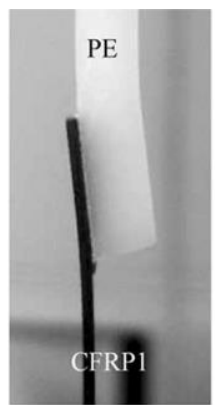

(c)

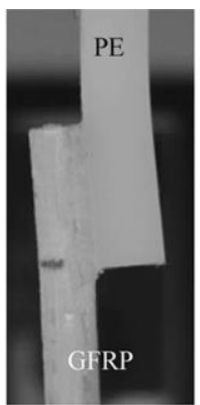

(d)

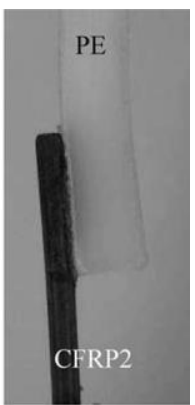

(e)

FIGURE 13 Deformed shape of the (a) PE=PE, (b) PE=PP, (c) PE=CFRP1, (d) PE=GFRP and (e) PE=CFRP2 SLJs immediately before failure. 


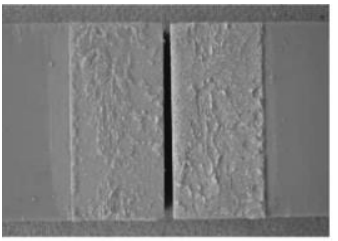

(a)

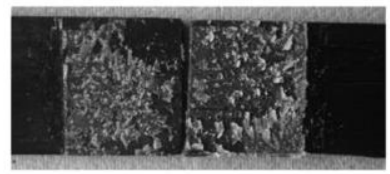

(b)

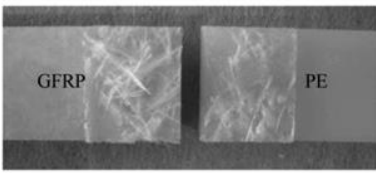

(c)

FIGURE 14 Example of cohesive failures on a (a) PE=PE and (b) CFRP2=CFRP2 SLJ, and (c) failure within the GFRP on a PE=GFRP SLJ.

decrease in the joints' stiffness up to failure ( $\mathrm{PE}=\mathrm{PE}, \mathrm{PE}=\mathrm{PP}$, $\mathrm{PE}=\mathrm{GFRP}$, and PE=CFRP2 joints), while in the case of extremely stiff adherends (GFRP=GFRP and CFRP2=CFRP2 joints), a shape similar to the pure Mode II cohesive law of the adhesive layer is observed on the $P$ - $d$ curves. This difference is justified by the practically absent differential deformation effects of the adherends in the GFRP=GFRP and CFRP2=CFRP2 joints, due to their stiffness compared with the adhesive. This leads to a practically equal magnitude of shear stresses in the adhesive layer along the entire overlap length (Fig. 8) [37-39]. Consequently, and given that in these cases shear stresses govern the adhesive layer behaviour, the $P d$ curves reflect the shape of the pure Mode II cohesive law. Considering the GFRP=GFRP (Fig. 16) and

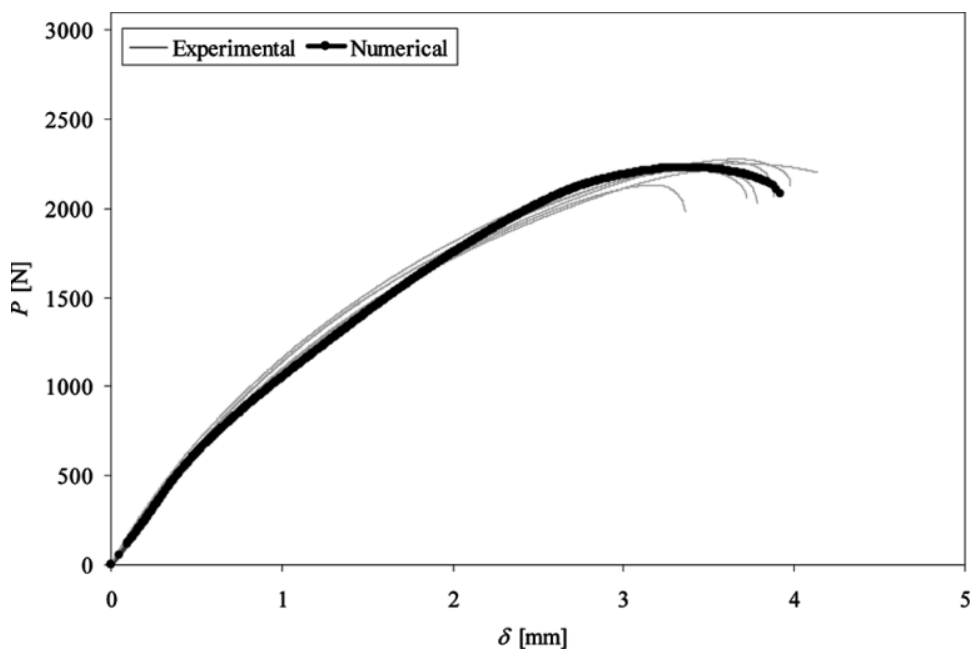

FIGURE 15 Comparison between the experimental and numerical $P$ - $d$ curves for the PE=PE SLJ. 


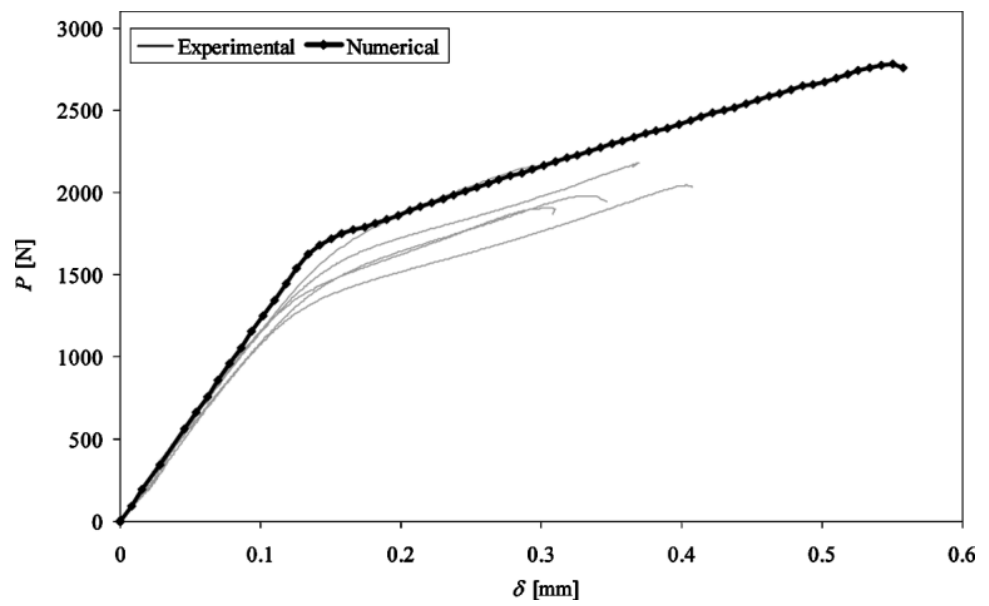

FIGURE 16 Comparison between the experimental and numerical $P-d$ curves for the GFRP=GFRP SLJ.

$\mathrm{PE}=\mathrm{GFRP}$ (Fig. 19) joints, since failure occurred experimentally within the GFRP adherends, smaller strengths were obtained, compared with the respective numerical predictions (which correspond to a cohesive failure of the adhesive layer). These failures within the GFRP adherends were deemed to occur due to the lower strength and fracture properties of this material, compared with the adhesive

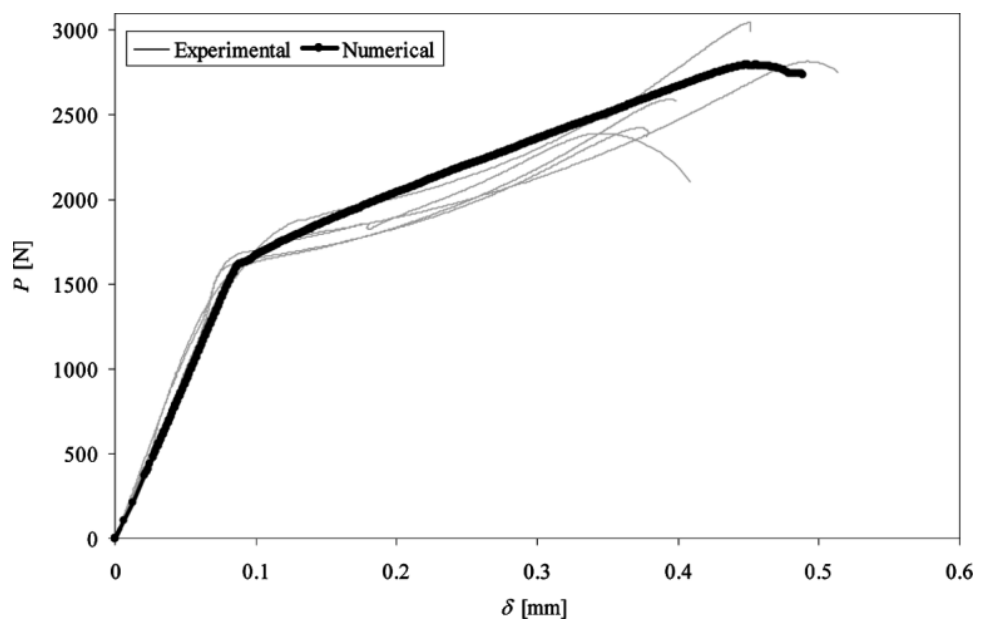

FIGURE 17 Comparison between the experimental and numerical $P-d$ curves for the CFRP2=CFRP2 SLJ. 


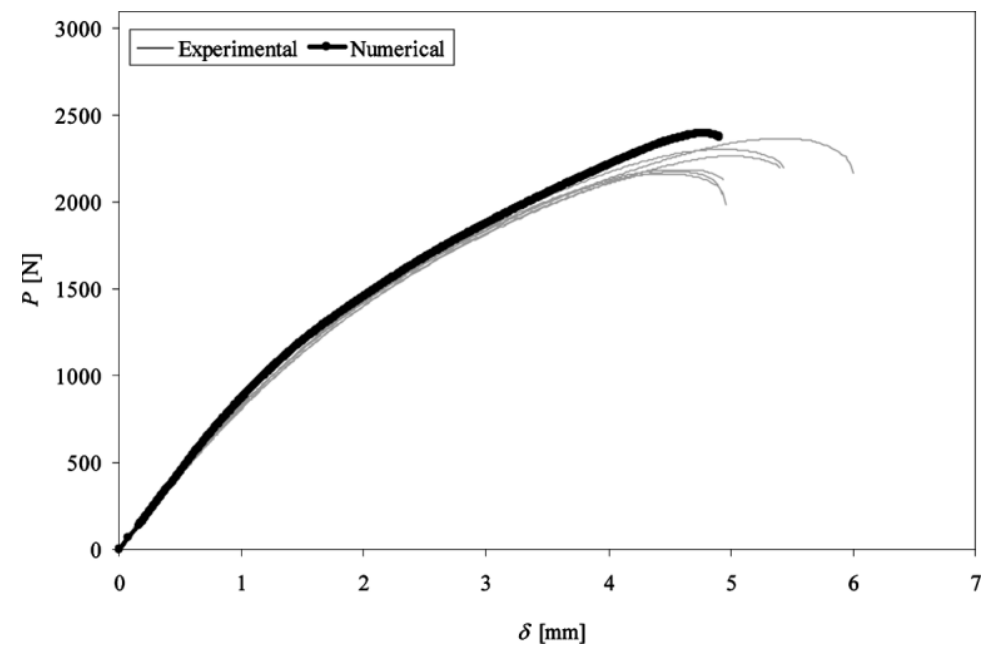

FIGURE 18 Comparison between the experimental and numerical $P$ - $d$ curves for the PE=PP SLJ.

layer cohesive properties. Even though failure within the adherends was not addressed numerically, a stress analysis for the PE=GFRP and GFRP=GFRP joints was performed to clarify this issue. $r_{\mathrm{y}}$ and $s_{\mathrm{xy}}$ stresses were evaluated at three different planes in the joints thickness (Fig. 21): within the lower adherend at a distance of $0.3 \mathrm{~mm}$

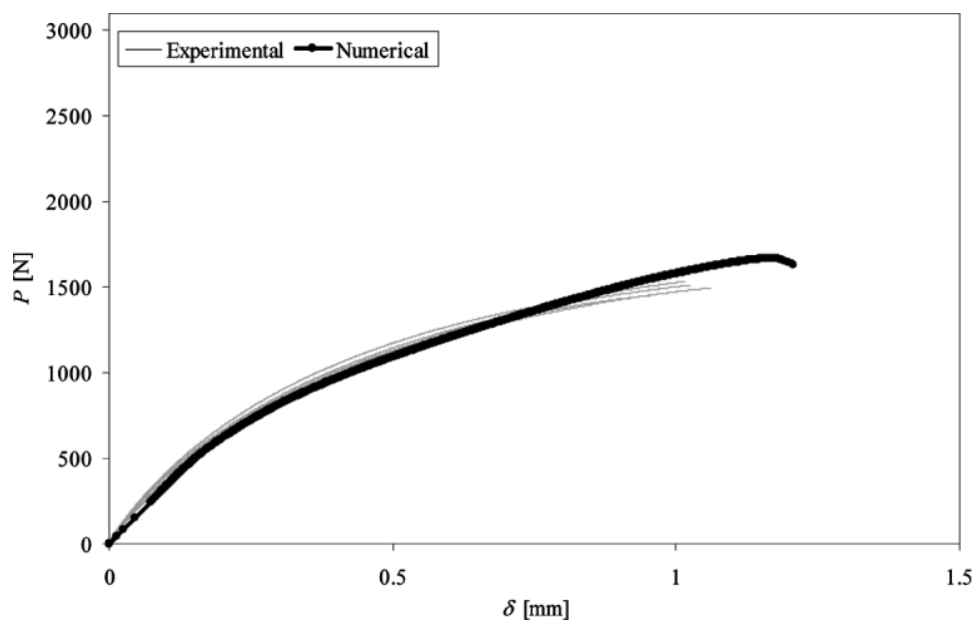

FIGURE 19 Comparison between the experimental and numerical $P-d$ curves for the PE=GFRP SLJ. 


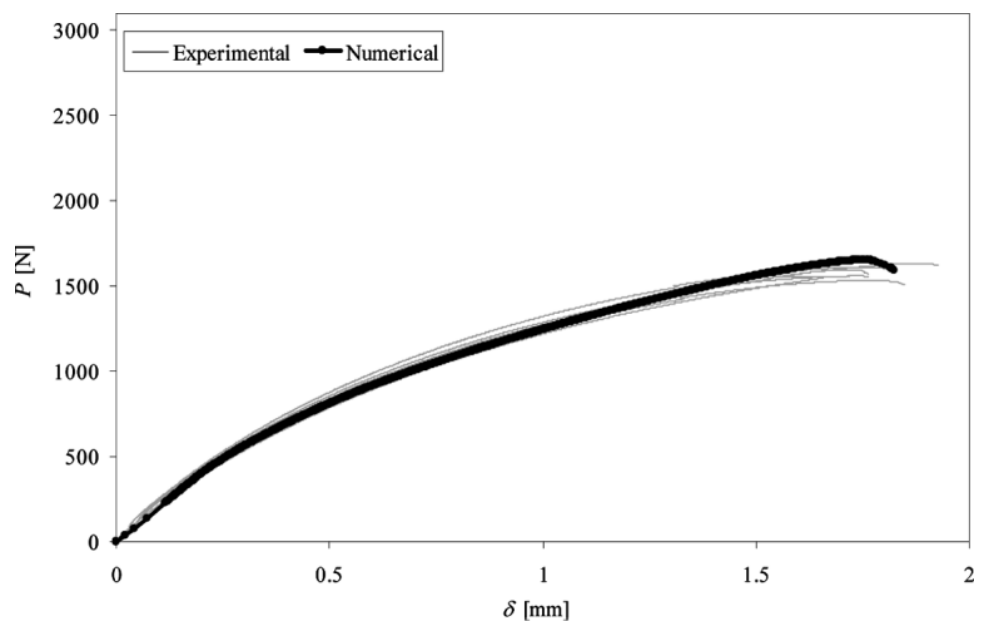

FIGURE 20 Comparison between the experimental and numerical $P-d$ curves for the PE=CFRP2 SLJ.

to the adherend=adhesive interface (plane P1), in the adhesive layer (plane P2), and within the upper adherend at a distance of $0.3 \mathrm{~mm}$ to the adhesive=adherend interface (plane P3). Planes P1 and P3 loci were based on the visual observations of the fractured tested specimens. Figures 22 and 23 show (a) $r_{\mathrm{y}}$ and (b) $s_{\mathrm{xy}}$ stress distributions for the PE=GFRP SLJ, while Figs. 24 and 25 correspond to the GFRP=GFRP SLJ. In these figures, $r_{\mathrm{y}}$ and $s_{\mathrm{xy}}$ stresses are normalized by $s_{\text {avg }}$, the average shear stress at plane P2 along the bond length for the respective joint, allowing for a direct comparison between the three planes. These figures show that $r_{\mathrm{y}}$ and $s_{\mathrm{xy}}$ peak stresses are

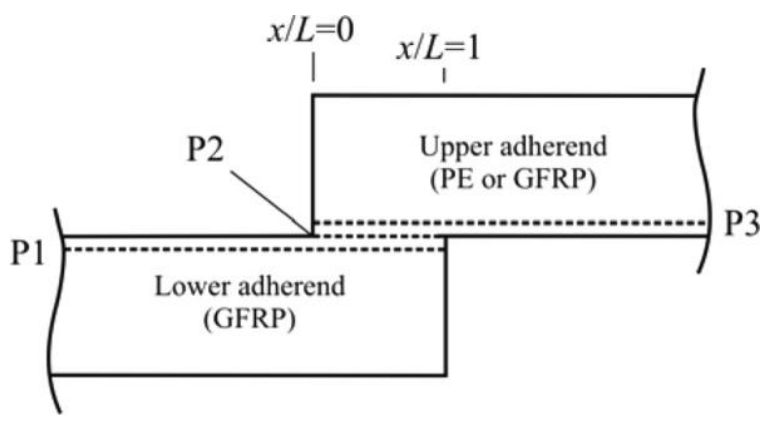

FIGURE 21 Planes for the evaluation of the stress distributions in the $\mathrm{PE}=\mathrm{GFRP}$ and GFRP=GFRP SLJ. 


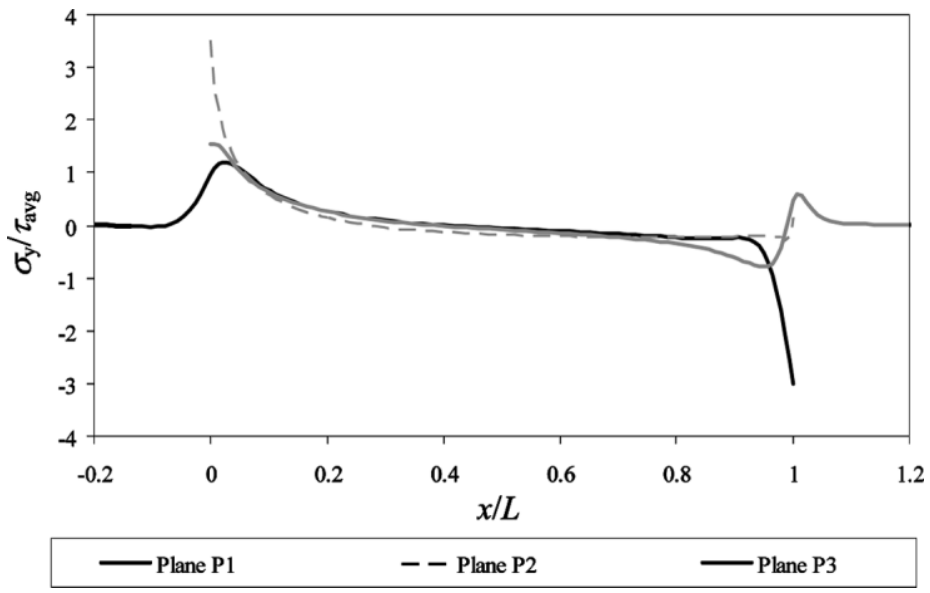

FIGURE $22 r_{\mathrm{y}}$ stress distributions at three planes for the PE=GFRP SLJ.

always highest at plane P2, demonstrating that the failures within the GFRP near the adherend=adhesive interface are caused by a strength lower than that of the adhesive layer.

\subsection{Experimental - Numerical Comparison}

Figure 26 compares the experimental and numerical values of $s_{\mathrm{m}}$ for (a) the joints with similar adherends and (b) joints combining PE with

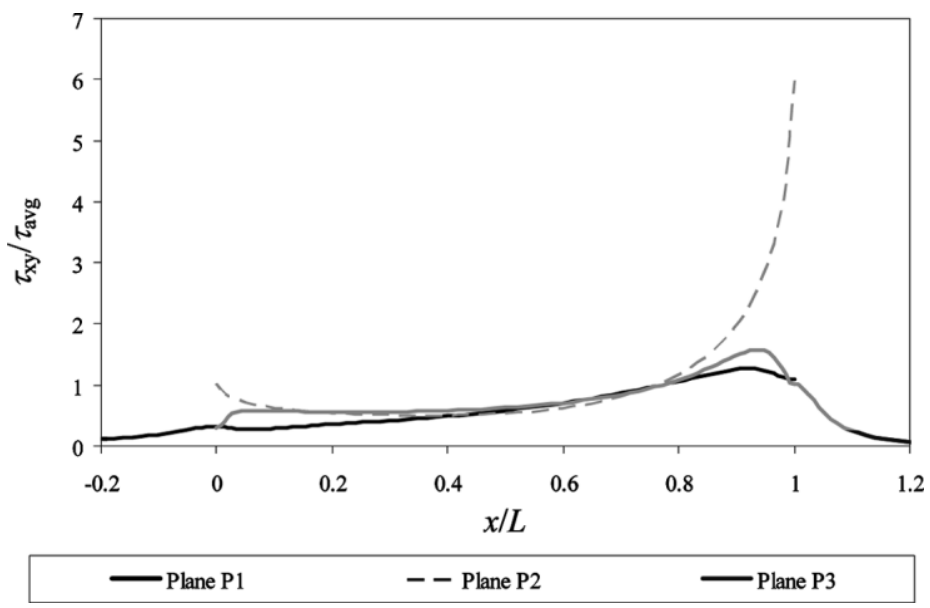

FIGURE $23 s_{\mathrm{xy}}$ stress distributions at three planes for the PE=GFRP SLJ. 

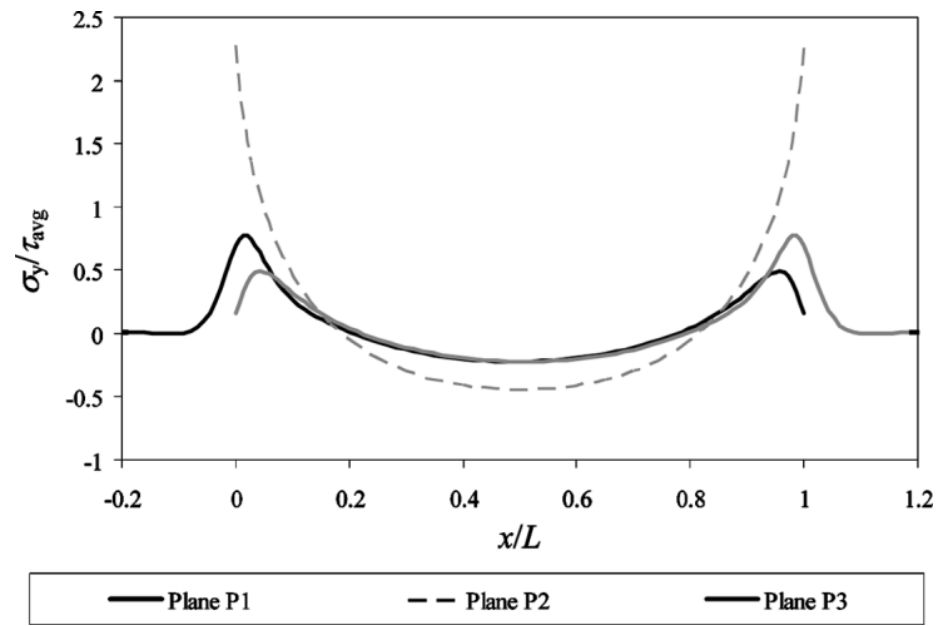

FIGURE $24 r_{\mathrm{y}}$ stress distributions at three planes for the GFRP=GFRP SLJ.

other materials. As it could previously be checked in Section 5.3, accurate results were obtained with the proposed numerical methodology. Only for the joints including GFRP adherends did the numerical predictions overestimate the experimental results. As mentioned earlier, this was caused by experimental failures within the GFRP adherends, whose strength proved to be lower than that of the

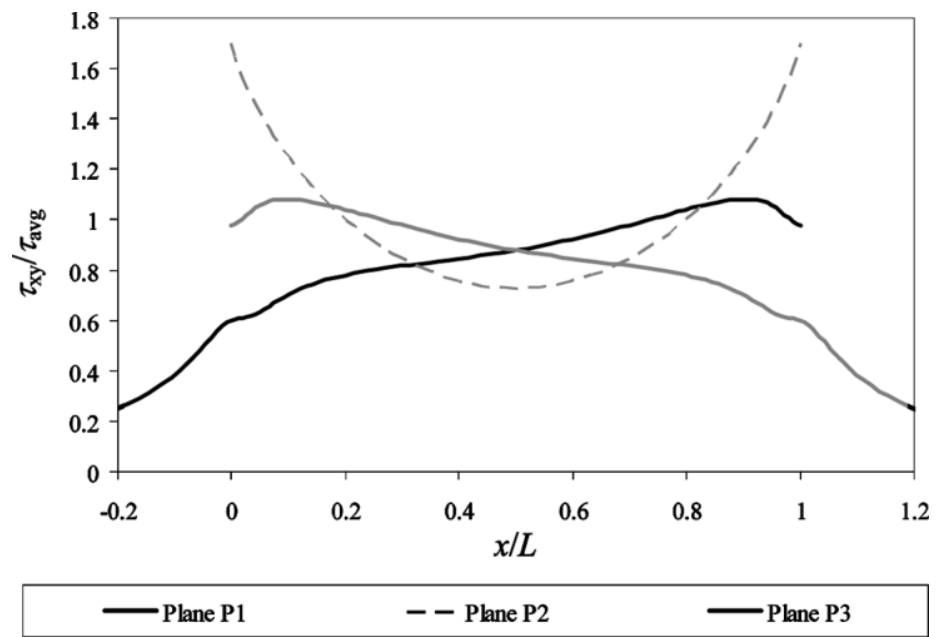

FIGURE $25 s_{\mathrm{xy}}$ stress distributions at three planes for the GFRP=GFRP SLJ. 
adhesive layer. The increasing trends observed on $s_{\mathrm{m}}$ in both cases are explained by a smaller bending of the joints as the stiffness of both adherends (Fig. 26a) or one of the adherends (Fig. 26b) increases, with a corresponding reduction in $r_{\mathrm{y}}$ peel and $s_{\mathrm{xy}}$ peak stresses at the damage onset loci (overlap edges).

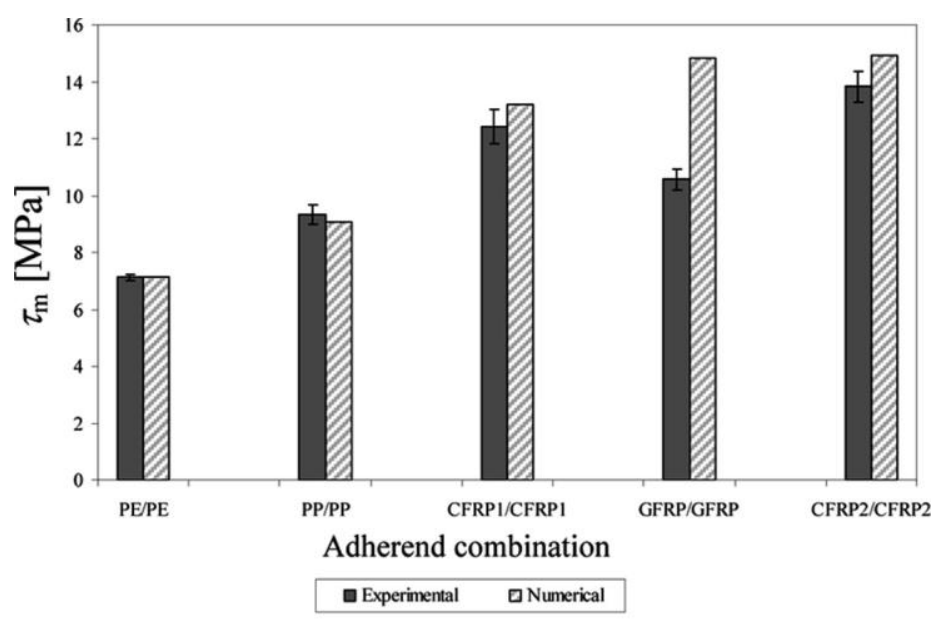

(a)

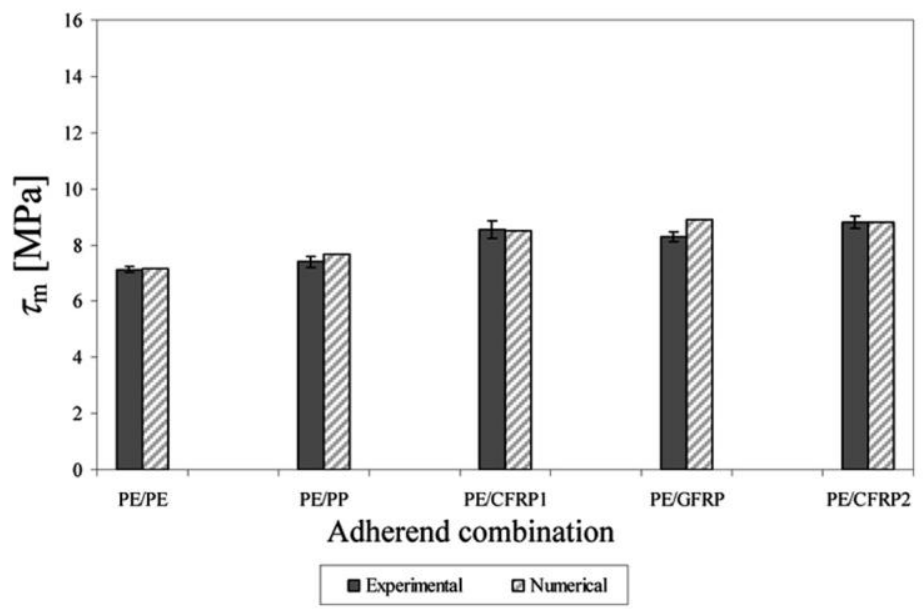

(b)

FIGURE 26 Summary of the experimental and numerical values of $s_{\mathrm{m}}$ for (a) the SLJs with similar adherends and (b) SLJs combining PE with other materials. 


\section{CONCLUDING REMARKS}

In this study, the tensile strength of single-lap joints between similar and dissimilar adherends bonded with an acrylic adhesive was evaluated. The experiments were used to validate a developed trapezoidal mixed-mode (IpII) cohesive damage model based on the indirect use of fracture mechanics and implemented within interface finite elements to simulate an adhesive layer of $3 \mathrm{M} \mathrm{DP}-8005^{I}$. The cohesive laws, used to reproduce the adhesive layer, present an increasing stress plateau to simulate the experimentally observed behaviour of this particular adhesive. Different techniques were used to derive the two pure mode laws. The following materials were considered as adherends: polyethylene, polypropylene, and carbon-epoxy and glass-polyester composites. Combinations of polyethylene with the remaining materials were also evaluated. A stress analysis of through-thickness normal and shear stresses in the adhesive layer was initially carried out to assess the influence of the adherends' stiffness on the stress distributions along the overlap and, correspondingly, on the strength of the joints. It was verified that increasing the adherends' stiffness leads to a reduction of the joint bending, which diminished stresses at the overlap edgesand, consequently, increased the strength of the joints. The numerical simulations captured fairly accurately the experimental behaviour of the joints, in terms of stiffness, and maximum load and the corresponding displacement. Only in some cases, where failures within the adherends occurred experimentally, did the numerical predictions overestimate the strength of the joints. In light of the results obtained, it is concluded that the proposed methodology to simulate the mechanical behaviour of bonded joints is adequate for the adhesive used.

\section{ACKNOWLEDGEMENTS}

The authors would like to thank Instituto de Engenharia Mecânica e Gestâo Industrial (INEGI) and Faculdade de Engenharia da Universidade do Porto (FEUP) for technical assistance. The first author wishes to thank Insitituto Politécnico do Porto=Instituto Superior de Engenharia do Porto (IPP=ISEP) for relief from teaching duties to complete the Ph.D. and Programa de Desenvolvimento Educativo para Portugal III (PRODEP III) for financial support.

\section{REFERENCES}

[1] Green, M. D., Guild, F. J., and Adams, R. D., Int. J. Adhes. Adhes. 22, 81-90 (2002).

[2] Noeske, M., Degenhardt, J., Strudthoff, S., and Lommatzsch, U., Int. J. Adhes. Adhes. 24, 171-177(2004). 
[3] Oosterom, R., Ahmed, T. J., Poulis, J. A., and Bersee, H. E. N., Med. Eng. Phys. 28, 323-330 (2006).

[4] Strobel, M., Jones, V., Lyons, C. S., Ulsh, M., Kushner, M. J., Dorai, R., and Branch, M.C., Plasmas Polym. 8, 61-95(2003).

[5] Bhowmik, S., Chaki, T. K., Ray, S., Hoffman, F., and Dorn, L., Int. J. Adhes. Adhes. 24, 461-470 (2004).

[6] Zou, G. P., Shalin, K., and Taheri, F., Compos. Struct. 65, 499-510 (2004).

[7] Bogdanovich, A. E. and Kizhakkethara, I., Compos. Part B - Eng. 30, 537-551 (1999).

[8] Chen, J., J. Thermoplast. Compos. 15, 429-441 (2002).

[9] Gonçalves, J. P. M., de Moura, M. F. S. F., Magalhães, A. G., and de Castro, P. M. S. T., Fatigue Fract. Eng. M. 26, 479-486 (2003).

[10] Campilho, R. D. S. G., de Moura, M. F. S. F., and Domingues, J. J. M. S., Compos. Sci. Technol. 65, 1948-1958 (2005).

[11] Valoroso, N. and Champaney, L., Eng. Fract. Mech. 73, 2774-2801 (2006).

[12] Campilho, R. D. S. G., de Moura, M. F. S. F., and Domingues, J. J. M. S., J. Adhes. Sci. Technol. 21, 855-870 (2007).

[13] Campilho, R. D. S. G., de Moura, M. F. S. F., Pinto, A. M. G., Morais, J. J. L., and Domingues, J. J. M. S., Compos. Part B - Eng. 41, 149-157 (2009).

[14] Tvergaard, V. and Hutchinson, J. W., J. Mech. Phys. Solids 41, 1119-1135(1993).

[15] Tvergaard, V. and Hutchinson, J. W., J. Mech. Phys. Solids 44, 789-800 (1996).

[16] Yang, Q. D., Thouless, M. D., and Ward, S. M., Int. J. Solids Struct. 38, 3251-3262 (2001).

[17] Campilho, R. D. S. G., de Moura, M. F. S. F., and Domingues, J. J. M. S., Int. J. Solids Struct. 45, 1497-1512 (2008).

[18] Kafkalidis, M. S. and Thouless, M. D., Int. J. Solids Struct. 39, 4367-4383 (2002).

[19] Thouless, M. D., Waas, A. M., Schroeder, J. A., and Zavattieri, P. D., Eng. Fract. Mech. 73, 64-78 (2006).

[20] Andersson, T. and Stigh, U., Int. J. Solids Struct. 41, 413-434 (2004).

[21] Leffler, K., Alfredsson, K. S., and Stigh, U., Int. J. Solids Struct. 44, 530-545 (2007).

[22] Hogberg, J. L. and Stigh, U., Eng. Fract. Mech. 73, 2541-2556 (2006).

[23] ASTM D 4501-01, Standard Test Method for Shear Strength of Adhesive Bonds Between Rigid Substrates by the Block Shear Method, (ASTM, West Conshohocken, PA, 2001).

[24] Yang, Q. D., Thouless, M. D., and Ward, S. M., J. Mech. Phys. Solids 47, 1337-1353 (1999).

[25] Pinto, A. M. G., Magalhães, A. G., Silva, F. G., and Baptista, A. P. M., Int. J. Adhes. Adhes. 28, 452-456 (2008).

[26] ASTM D 3163-01, Standard Test Method for Determining Strength of Adhesively Bonded Rigid Plastic Lap-Shear Joints in Shear by Tension Loading, (ASTM, 2004).

[27] ASTM D 1002-01. Standard Test Method for Apparent Shear Strength of SingleLap-Joint Adhesively Bonded Metal Specimens by Tension Loading (Metal- toMetal), (ASTM, 2004).

[28] Hu, F. Z. and Soutis, C., Compos. Sci. Technol. 60, 1103-1114 (2000).

[29] Magalhães, A. G., de Moura, M. F. S. F., and Gonçalves, J. P. M., Int. J. Adhes. Adhes. 25, 313-319 (2005).

[30] da Silva, L. F. M. and Adams, R. D., Int. J. Adhes. Adhes. 27, 227-235 (2007).

[31] Chaves, F. J. P., da Silva, L. F. M, and de Castro, P. M. S. T., J. Mater. Des. Appl. 222, 159-174 (2008).

[32] Cognard, J. Y., Davies, P., Sohier, L., and Créac'hcadec, R., Compos. Struct. 76, 34-46 (2006). 
[33] Kilic, B., Madenci, E., and Ambur, D. R., Eng. Fract. Mech. 73, 1472-1490 (2006).

[34] Campilho, R. D. S. G., de Moura, M. F. S. F., Domingues, J. J. M. S., and Morais, J. J. L., J. Adhes. Sci. Technol. 22, 1565-1591(2008).

[35] Kim, K. S., Yoo, J. S., Yi, Y. M., and Kim, C. G., Compos. Struct. 72, 477-485 (2006).

[36] Campilho, R. D. S. G., de Moura, M. F. S. F., and Domingues, J. J. M. S., Int. J. Adhes. Adhes. 29, 195-205 (2009).

[37] Volkersen, O., Luftfahrtforsch. 15, 41-47 (1938).

[38] Adams, R. D., Comyn, J. C., and Wake, W. C., Structural Adhesive Joints in Engineering, (Chapman \& Hall, London, 1997).

[39] Adams, R. D. and Comyn, J. C., Assembly Autom. 20, 109-117(2000). 